\title{
Adhesin-dependent binding and uptake of Salmonella enterica serovar Typhimurium by dendritic cells
}

\author{
Aizhen Guo, ${ }^{1} \dagger$ Melissa A. Lasaro, ${ }^{1}$ Jean-Claude Sirard, ${ }^{2} \ddagger$ Jean- \\ Pierre Kraehenbühl ${ }^{2}$ and Dieter M. Schifferli ${ }^{1}$ \\ ${ }^{1}$ University of Pennsylvania School of Veterinary Medicine, 3800 Spruce Street, Philadelphia, \\ PA 19104, USA \\ ${ }^{2}$ Swiss Institute for Experimental Cancer Research (ISREC), 1066 Epalinges, Switzerland
}

Correspondence

Dicter Schifferli

dmschiff@vet.upenn.edu

Received 19 July 2006

Revised 5 January 2007

Accepted 9 January 2007

\section{INTRODUCTION}

Salmonella enterica serotypes are correlated with different types of human and animal disease syndromes such as bacteraemia, typhoid fever and enterocolitis. S. enterica serotype Typhimurium is a highly evolved pathogen that has adapted to colonizing and surviving for long periods in humans, mice and other animal hosts. The virulence is partially attributed to its capacity to invade host cells.

After oral infection, S. enterica serotype Typhimurium colonizes the small intestine and preferentially enters Peyer's patches M cells (Jepson \& Clark, 2001). Thanks to the Salmonella type III secretion system (T3SS) encoded by Salmonella pathogenicity island 1 (SPI-1) (Galan, 2001; Lostroh \& Lee, 2001), Salmonella induce their uptake by non-phagocytic cells, such as intestinal epithelial cells. How important epithelial cell invasion is in vivo for crossing the intestinal barrier remains questionable, SPI-1 deletion

tPresent address: National Key Laboratory of Agricultural Microbiology, Lab of Animal Virology, College of Veterinary Medicine, Huazhong Agricultural University, Wuhan, 430070, PR China.

łPresent address: INSERM, U801, Institut de Pasteur de Lille, Institut de biologie, Groupe AVENIR d'Immunité Anti-Microbienne des Muqueuses, 1 rue du Pr Calmette - BP 447, 59021 Lille Cedex, France.

Abbreviations: DC, dendritic cell; FCS, fetal calf serum; PE, Rphycoerythrin. mutants being still enteroinvasive (Murray \& Lee, 2000). SPI-1 facilitates M cell invasion (Penheiter et al., 1997), but is not essential for entry by this route (Clark et al., 1998; Jepson \& Clark, 2001). The invading Salmonella cells that have translocated through the intestinal epithelial layer reach the subepithelial compartment where they interact most efficiently with dendritic cells (DCs) that reside under M cells or in M cell pockets (Hopkins et al., 2000). As a third uptake mechanism, CD18-expressing phagocytes were shown to transport Salmonella from the gastrointestinal tract to the bloodstream, suggesting a paracellular route of entry (Vazquez-Torres et al., 1999; Vazquez-Torres \& Fang, 2000). Such direct uptake has been visualized with intraepithelial DCs that send tight-junction-forming dendrites to the intestinal lumen (Niess et al., 2005; Rescigno et al., 2001), suggesting that CD18-expressing phagocytes are most probably DCs. DCs are found in the peripheral tissues, mainly as immature DCs that have high phagocytic and endocytic abilities. Immature DCs are widely spread in the lamina propria of the gut and can be recruited at the subepithelial site of infection through proinflammatory molecules, particularly chemokines expressed by the infected enterocytes (Didierlaurent et al., 2002; Sierro et al., 2001). Both host molecules and microbe-associated molecular pattern, such as lipopolysaccharide, peptidoglycan and flagellin, then participate in the maturation process of DCs. Maturing DCs lose their phagocytic properties and upregulate surface molecules, such as chemokine receptor 
CCR7 that initiates their migration to the mesenteric lymph node (Cheminay et al., 2002), as well as major histocompatibility complex and co-stimulatory molecules (e.g. CD80, CD86 and CD40) that serve to activate naïve T cells (Wick, 2002, 2003). Thus unique maturation steps empower DCs to become most effective antigen-presenting cells in their role as specialized messengers linking innate to adaptive immunity.

Although the uptake of S. enterica serotype Typhimurium in DCs remains an intensive field of study, very little is known about the bacterial molecules involved in the earliest recognition steps. S. enterica serotype Typhimurium produces a variety of fimbrial adhesins that have been shown to be involved in bacterial binding in murine intestines (van der Velden et al., 1998). Fimbriae are surface-exposed hair-like structures that consist of helically arranged protein subunits. Their adhesive properties are most frequently mediated by a minor tip subunit. The fimbrial subunits are typically encoded by a gene cluster, together with export, assembly and regulatory proteins. The current study investigated whether Salmonella fimbriae are involved in the initial interaction between bacteria and DCs. Our data provide evidence that the type 1 fimbriae, thanks to their adhesive subunit FimH, mediate the attachment of S. enterica serotype
Typhimurium to DCs, leading to a significantly increased SPI-1-independent bacterial internalization process.

\section{METHODS}

Bacterial strains and plasmids. S. enterica serotype Typhimurium and Escherichia coli strains and plasmids used in this study are detailed in Table 1 . Bacteria were routinely grown on LB medium supplemented with the appropriate antibiotics. All the transformants were prepared by high-voltage electroporation. Static broth cultures were performed at $37^{\circ} \mathrm{C}$ for $48 \mathrm{~h}$ to enrich for type 1 fimbriae. Expression of type 1 fimbriae was determined with antibodies, and expression of FimH and mannose-sensitive binding was screened by yeast cell (Saccharomyces cerevisiae) agglutination (Hancox et al., 1998). Salmonella type 1 fimbriae were also expressed as recombinant organelles on the surface of E. coli strains ORN103 or AAEC189, both lacking their own mannose-sensitive type 1 fimbrial genes (Table 1; designated fim or pil). E. coli ORN103(pKT303) was essentially non-fimbriated, suggesting a polar effect on the transcription of downstream regulatory genes (Table 1). Therefore, a new fim $H$ deletion mutant was constructed according to the following strategy. Long PCR was carried out to amplify all the type $1 \mathrm{fim}-$ brial genes encoding the structural and biogenesis proteins (fimAfimF) using pISF101 as the template, according to the manufacturer's protocol (Expand Long Template PCR; Roche Applied Science). The oligonucleotides were derived from the $5^{\prime}$ end of fim $A$ and a sequence complementary to $3^{\prime}$ end of fimF. NdeI and Bam HI sites were introduced into the upper and lower primer, respectively

Table 1. Strains and plasmids used in this study

\begin{tabular}{|c|c|c|}
\hline Strain or plasmid & Parental strain and relevant properties ${ }^{\star}$ & Source or reference \\
\hline \multicolumn{3}{|c|}{ S. enterica serotype Typhimurium } \\
\hline AJB3 & $\chi 4252\left(\mathrm{Nal}^{\mathrm{R}}\right)$, derived from SR-11 & Bäumler et al. (1996a, c); Lockman \& Curtiss (1992b) \\
\hline AJB4 & $\chi 4253\left(\mathrm{Nal}^{\mathrm{R}}\right)$, derived from SR-11 $\Delta$ fim & Bäumler et al. (1996a, c); Lockman \& Curtiss (1992b) \\
\hline ST100 & Typhimurium C5 sipB:: $\operatorname{Tn} 5\left(\mathrm{Km}^{\mathrm{R}}\right)$ & Hermant et al. (1995); Hersh et al. (1999) \\
\hline DMS1508 & AJB3 sipB:: Tn5 & This study \\
\hline DMS1509 & AJB4 sipB:: Tn5 & This study \\
\hline $\mathrm{LBH} 4$ & LB5010 fimH:: $\mathrm{Km}^{\mathrm{R}}$, derived from LT2 & Hancox et al. (1998) \\
\hline \multicolumn{3}{|l|}{ E. coli } \\
\hline BL21(DE3) & $\mathrm{F}$ ompT hsdS $S_{\mathrm{B}}\left(\mathrm{r}_{\mathrm{B}}^{-} \mathrm{m}_{\mathrm{B}}^{-}\right) \mathrm{gal} d c m(\mathrm{DE} 3)$ & Novagen, EMD Biosci. \\
\hline SE5000 & MC4100 recA $\left(\mathrm{Fim}^{-}\right)$ & Silhavy et al. (1984) \\
\hline ORN103 & $\begin{array}{l}\text { thr1 leu6 thi1 (argF-lac) U169 xyl7 ara13 mtl2 gal6 } \\
\text { rpsL fhuA2 minA minB recA13 } \triangle \text { (pilABCDFE hyp) }\end{array}$ & Maurer \& Orndorff (1987) \\
\hline AAEC189 & MM294 $\Delta$ lac recA endA $\Delta$ fim $\left(\mathrm{r}_{\mathrm{K}}^{-} \mathrm{m}_{\mathrm{K}}^{+}\right)$ & Blomfield et al. (1991) \\
\hline \multicolumn{3}{|l|}{ Plasmids } \\
\hline pISF101 & pACYC184 fimAICDHFZYWU $\left(\mathrm{Cm}^{\mathrm{R}}\right)$ & Thankavel et al. (1999) \\
\hline pKT303 & pISF101 $\Delta$ fimH (polar effects on downstream fim genes) & Thankavel et al. (1999) \\
\hline pET16b & Expression vector with a $\mathrm{T} 7$ promoter & Novagen \\
\hline pAZ24 & pET16b fimAICDHF & This study \\
\hline pAZ25 & pAZ24 $\Delta$ fimH (non-polar 33 bp deletion) & This study \\
\hline pAZ36 & pACYC184 fimAICDF & This study \\
\hline pISF204 & fimHFZ in $\mathrm{Ap}^{\mathrm{R}}$ plasmid & Hancox et al. (1998) \\
\hline pISF211 & pISF204 $\Delta$ fimH & Hancox et al. (1998) \\
\hline pKKGFP & pKK223.3 GFP $\left(\right.$ Ap $\left.^{\mathrm{R}}\right)$ & Hopkins et al. (2000) \\
\hline pGFPmut3.1 & pUC GFPmut3.1 $\left(\mathrm{Ap}^{\mathrm{R}}\right)$ & BD Biosciences, Clontech \\
\hline pAZ8 & pLG339 GFPmut3.1 $\left(\mathrm{Tc}^{\mathrm{R}}\right)$ & This study \\
\hline
\end{tabular}

${ }^{\star}$ Ap, Ampicillin; Cm, chloramphenicol; Km, kanamycin; Nal, nalidixic acid; Tc, tetracycline. 
(upper primer, 5'-GGAATTCCATATGAGACATAAATTAATGAC3'; lower primer, 5'-CGGGATCCTTACTAATTGTAATTGATCAG$\left.3^{\prime}\right)$. The product was cloned into pET16b to obtain pAZ24. A 33-bp internal segment of $f i m H$ in pAZ24 was removed by StuI restriction and self-ligation to obtain pAZ25. The deletion was confirmed by checking for the loss of an internal ClaI site. Plasmid pAZ24 or pAZ25 was introduced into BL21(DE3) by electroporation, and fim and fimH gene expression was checked after IPTG induction. Both transformants produced type 1 fimbriae, but only BL21(DE3)(pAZ24) agglutinated yeast cells. The fimbrial gene cluster of pAZ25 was cloned as a BglII-BamHI DNA fragment into the BamHI site of pACYC184, in the opposite orientation to the tetracycline resistance gene, to obtain pAZ36. E. coli AAEC189(pAZ36) was shown to express fimbriae constitutively without agglutinating yeast cells.

Preparation of antiserum to type 1 fimbriae. The Salmonella type 1 fimbriae expressed by E. coli SE5000(pISF101) were purified as described by Dodd \& Eisenstein (1982). SDS-PAGE and Coomassie blue staining confirmed the preparation's purity. Antifimbrial antibodies were raised in rabbits (Cocalico Biologicals) with resulting serum ELISA titres of $>100000$. The antibodies were shown to agglutinate type 1 fimbriated Salmonella or recombinant E. coli expressing Salmonella type 1 fimbriae.

DC preparation. Murine bone-marrow-derived DCs were prepared as described by Inaba et al. (1992) and Lutz et al. (1999). Briefly, 6to 8 -week-old BALB/c mice were sacrificed, and the femurs and tibias were harvested. Bone marrow was flushed out of the shafts and cells seeded into Petri dishes with complete RPMI 1640 media (Glutamax; Gibco) supplemented with $20 \mathrm{ng}$ murine recombinant granulocyte/macrophage colony-stimulating factor $\mathrm{ml}^{-1}$ (rGM-CSF; Pepro Tech Inc. or R\&D Systems), $10 \%$ fetal calf serum (FCS), $1 \mathrm{mM}$ sodium pyruvate, $50 \mu \mathrm{M} \beta$-mercaptoethanol, $100 \mathrm{U}$ penicillin $\mathrm{ml}^{-1}, 100 \mu \mathrm{g}$ streptomycin $\mathrm{ml}^{-1}$ and $100 \mu \mathrm{g}$ gentamicin sulfate $\mathrm{ml}^{-1}$. For some experiments, bone marrow was depleted of red blood cells, $\mathrm{T}$ and $\mathrm{B}$ cells before differentiation of precursors into DCs (Niedergang et al., 2000). The cells were incubated at $37^{\circ} \mathrm{C}$ in a humidified incubator with $5 \% \mathrm{CO}_{2}$ for either 6-7 days (Inaba et al., 1992) or 10 days with media changes every 3 days (Lutz et al., 1999). The non-adherent cells were harvested, and DCs were defined by expression of the surface markers (CD11c, MHC-II, CD40, CD80, CD86) using antibodies conjugated to FITC, R-phycoerythrin (PE) or biotin (Pharmingen; BD Biosciences). Isotype controls were FITC- and PE-labelled non-specific antibodies, and streptavidineconjugated FITC or PE were used to detect biotinylated antibodies. The immature dendritic cells were characterized by high-level expression of CD11c $\left(\mathrm{CD}_{11 \mathrm{c}^{+}}\right)$, low- to intermediate-level expression of MHC II, low-level expression of CD80 and CD86, and no expression of CD40.

Microscopy. Bacterial adhesion to DCs was examined by light microscopy. DCs $\left(3.3 \times 10^{5}\right.$ cells $\left.\mathrm{ml}^{-1}\right)$ in RPMI medium without FCS and antibiotics were mixed with PBS-washed S. enterica serotype Typhimurium or recombinant E. coli grown statically for $48 \mathrm{~h}$ at an m.o.i. of 100 . Bacteria and DCs were incubated at $37^{\circ} \mathrm{C}$ on a rotating wheel at 15 r.p.m. At various time points, slides were prepared with a cytospin centrifuge (800 r.p.m., $5 \mathrm{~min}$ ), air-dried, fixed in $4 \%$ paraformaldehyde and Giemsa-stained. Bacteria-cell interactions were recorded by counting the number of bacteria co-localizing with DC in $\geqslant 10$ fields per slide. For some experiments, DCs were pretreated with cytochalasin $\mathrm{D}\left(5 \mu \mathrm{g} \mathrm{ml}{ }^{-1}\right)$ for $10 \mathrm{~min}$ at $37^{\circ} \mathrm{C}$ before the addition of bacteria.

Interactions of Salmonella with DCs or HeLa cells. The standard invasion assay by gentamicin resistance (Elsinghorst, 1994; Lee et al., 1992) was modified as follows. The bacteria (m.o.i. $=12.5$ ) were added to DCs $\left(1 \times 10^{6}-2 \times 10^{6}\right.$ cells $)$ and incubated for $1 \mathrm{~h}$ at $37^{\circ} \mathrm{C}$ on a rotating wheel. The extracellular bacteria were removed by washing three times with RPMI1640 medium containing $50 \mu \mathrm{g}$ gentamicin $\mathrm{ml}^{-1}$. The cells were further incubated for $1 \mathrm{~h}$ in RPMI1640 medium containing $50 \mu \mathrm{g} \mathrm{ml}^{-1}$ gentamicin at $37^{\circ} \mathrm{C}$. DCs were then washed three times with PBS, lysed with $0.5 \%$ Triton X-100 in PBS for 10 min and live Salmonella counted by a standard plating technique. The colony numbers for the wild-type strain AJB3 were normalized to $100 \%$ for comparisons with the numbers of the other Salmonella strains. The human HeLa epithelial cell line (ATCC CCL-2) was cultured in Dulbecco's modified Eagle medium (Gibco) supplemented with $10 \%$ FCS and $1 \mathrm{mM}$ nonessential amino acids (Gibco) at $37^{\circ} \mathrm{C}$ in an atmosphere containing $5 \% \mathrm{CO}_{2}$. Monolayers were prepared by seeding $2 \times 10^{5}$ cells into each well of a 24-well tissue culture plate and incubating for $48 \mathrm{~h}$ at $37^{\circ} \mathrm{C}$ in a humidified atmosphere of $5 \% \mathrm{CO}_{2}$ in air. Bacteria were added to the cells at an m.o.i. of $20: 1$ to $200: 1$. Bacteria were incubated with cell monolayers for $1 \mathrm{~h}$ at $37^{\circ} \mathrm{C}$ in $5 \% \mathrm{CO}_{2}$ before being washed three times with PBS. Extracellular bacteria were killed by incubating the cells in medium containing $50 \mu \mathrm{g}$ gentamicin $\mathrm{ml}^{-1}$ for an additional $90 \mathrm{~min}$. After three PBS-washing steps, the cell monolayers were lysed with cold $0.1 \%$ Triton X-100 and viable counts were determined as described above.

Flow cytometry binding and uptake assays. Bacterial and fimbrial adhesion to DCs, as well as bacterial uptake by DCs, was examined by flow cytometry. Bacteria transformed with a GFP-expressing plasmid and other appropriate compatible plasmids (Table 1) were grown statically. Initial experiments were undertaken with high-copy-number pKKGFP-transformed S. enterica serotype Typhimurium. However, the percentage of fluorescent bacteria grown statically for 2 days was frequently under $50 \%$, suggesting plasmid loss. Thus, later experiments took advantage of the low-copy-number and stable plasmid construct pAZ8. Although the fluorescence intensity of Salmonella-associated DCs was lower with pAZ8- than with pKKGFP-containing bacteria, all bacteria associated to DCs were detectable. Bacteria were collected by centrifugation, washed and resuspended in $4{ }^{\circ} \mathrm{C}$ PBS. Bacterial numbers were estimated by $\mathrm{OD}_{600}$ and checked by colony counts (c.f.u. $\mathrm{ml}^{-1}$ ). DCs were harvested and cell viability ( $\geqslant 90 \%$ ) was tested by Trypan Blue staining. Bacteria and DCs were incubated at $4{ }^{\circ} \mathrm{C}$ for various times at an m.o.i. of 50 with gentle end-to-end agitation. Unbound bacteria were removed from DCs by three to five washes in PBS. DCs were further incubated with anti-CD11c-PE antibodies for 30-60 min in the dark at $4{ }^{\circ} \mathrm{C}$ with gentle end-to-end agitation. After three to five washing steps, cells were resuspended in 300-500 $\mu \mathrm{l}$ cold RPMI 1640 for flow cytometry (FACScan or FACSCalibur with CellQuest pro software; BD Biosciences). For the binding inhibition assay, bacteria were incubated with DCs in the presence of $100 \mathrm{mM} \alpha$-methyl mannoside for $1 \mathrm{~h}$. To study the binding of type 1 fimbriae to DCs, purified fimbriae of strain AJB3 were biotinylated with sulfo-NHSLC-Biotin (Pierce), according to the manufacturer's instructions. Biotinylated fimbriae were incubated in $2 \%$ FCS-PBS with DCs at $4{ }^{\circ} \mathrm{C}$ for $1 \mathrm{~h}$. PE-conjugated streptavidin was used to probe the biotinylated fimbriae that remained attached to DCs after three to five washes.

The uptake of bacteria by DCs was also examined by flow cytometry. Bacteria and DCs were incubated for $30 \mathrm{~min}$ at $37^{\circ} \mathrm{C}$ on a rotating wheel $(\mathrm{m} .0 . i .=50)$, washed three to five times and the cells fixed with $4 \%$ paraformaldehyde. The cells were then divided into two groups, one group being permeabilized with $0.5 \%$ Triton X-100 at room temperature for $10 \mathrm{~min}$. Cells were then labelled with rabbit antiSalmonella $\mathrm{O}$ antigen factor 4 antiserum (Difco, BD Diagnostic Systems), sequentially followed by biotin-conjugated goat anti-rabbit IgG and FITC-conjugated streptavidin or Alexa Fluor488 anti-rabbit IgG (Invitrogen, Molecular Probes). The DCs were probed with PEconjugated anti-CD11c IgG. The non-permeabilized cells were used to 
determine the extracellular bound bacteria, while the permeabilized cells were interpreted as representing all the DC-associated bacteria, namely both the extra- and intracellular Salmonella.

Statistical analysis. Groups of data were compared with the unpaired Student's $t$-test, using an unequal variance $t$-test when needed, as determined by the F-test (Zar, 1974). Probability $(P)$ values of less than 0.05 indicated that the groups were significantly different.

\section{RESULTS}

\section{Adhesion of type 1 fimbriated S. enterica serotype Typhimurium to DCs}

To characterize interaction of DCs with bacteria, cells were incubated at $37^{\circ} \mathrm{C}$, followed by extensive washing, Giemsa staining and analysis by light microscopy. S. enterica serotype Typhimurium grown statically interacted better with DCs than bacteria grown overnight or in exponential growth phase under aerated conditions (data not shown). Since Salmonella produce large amounts of type 1 fimbriae when grown statically, we hypothesized that the type 1 fimbriae were involved in bacterial association to DCs. The interactions of $S$. enterica serotype Typhimurium AJB3 and its non-fimbriated fim derivative AJB4 with DCs were compared over time (Fig. 1). The association of wild-type bacteria with DCs was low or not detectable at $5 \mathrm{~min}$ and increased gradually over time. The interaction of the fimbriated bacteria was about three- and fivefold more effective at 30 and $60 \mathrm{~min}$, respectively, compared to the fim mutant (Fig. 1b). Type 1 fimbriated Salmonella bound significantly better to cytochalasin D-treated DCs at $30 \mathrm{~min}$ $\left[0.72 \pm 0.10\right.$ Salmonella Fim $^{+}$per DC versus $0.10 \pm 0.03$ Salmonella Fim ${ }^{-}$per DC (means \pm SE, $P<0.01$ )] and $60 \mathrm{~min}$ $\left(2.97 \pm 0.54\right.$ Salmonella Fim $^{+}$versus $0.20 \pm 0.06$ Salmonella Fim $^{-}, P<0.01$ ), indicating that the interaction was independent of actin polymerization and phagocytosis. To specifically assess binding of bacteria to DC, flow cytometry assays were undertaken at $4{ }^{\circ} \mathrm{C}$. Treatment at $4{ }^{\circ} \mathrm{C}$ impairs any internalization events and was observed to slow down DC aggregation. Bacteria-associated DCs were identified by using GFP-expressing bacteria and PE-anti-CD11c-labelled DCs. Moreover, to exclude any effect of the Salmonella type III secretion system SPI-1 in attachment, we constructed fimbriated and non-fimbriated bacteria deficient for SipB. After a $30 \mathrm{~min}$ bacteria/DC incubation, the type 1 fimbriated strain associated with most DCs ( $92 \%)$, whereas no significant binding was detected with the non-fimbriated bacteria (Fig. 1c). Taken together, the flow cytometry data supported the microscopic observation that S. enterica serotype Typhimurium type 1 fimbriae are critical for bacterial adhesion to DCs.

\section{Fimbriae-specific binding to DCs}

To confirm that the binding of bacteria to DCs was mediated by type 1 fimbriae, experiments were performed with an $E$. coli fim operon deletion mutant (ORN103) that was complemented with either plasmid pISF101 harbouring Salmonella type 1 fimbrial genes or pKT303, which is (a)

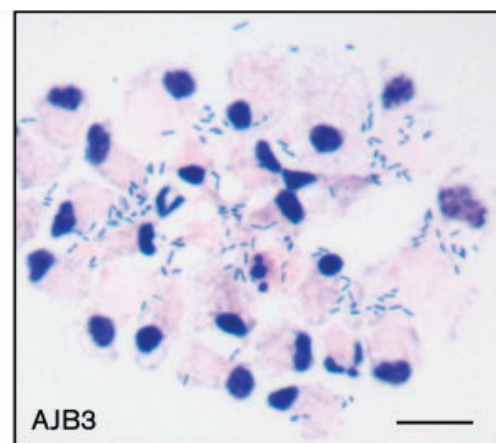

(b)

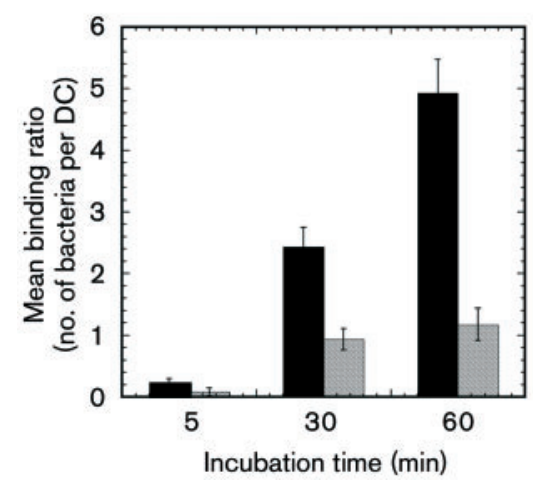

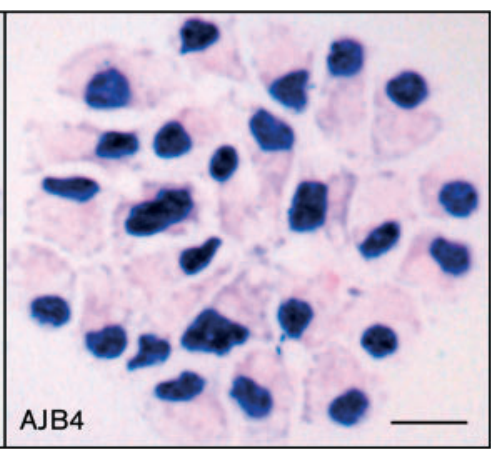

(c)

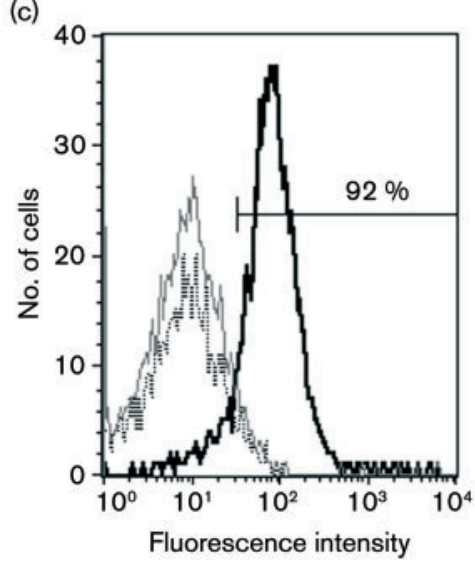

Fig. 1. Type 1 fimbriae-dependent binding of S. enterica serotype Typhimurium to DCs. (a) Giemsa-stained DCs and S. enterica serotype Typhimurium AJB3 and AJB4 (fim) incubated at $37^{\circ} \mathrm{C}$ for $60 \mathrm{~min}$ at an m.o.i. of 100 . Bars, $40 \mu \mathrm{m}$. (b) Bacteria were incubated with DCs at $37^{\circ} \mathrm{C}$ for 5,30 and $60 \mathrm{~min}$. The numbers of bacteria associated with DCs were counted microscopically. The bars represent the mean \pm SE values for AJB3 (filled bars) and AJB4 (shaded bars) of three experiments. There were statistically significant differences for the 30 and $60 \mathrm{~min}$ values $(P<0.01)$. (c) Binding of type 1 fimbrial $S$. enterica serotype Typhimurium DMS1508 (sipB). Bacteria were transformed with the GFP-expressing plasmid pAZ8. Only CD $11 \mathrm{c}^{+}$-gated cells (DCs) are shown. DCs and bacteria were incubated for $30 \mathrm{~min}$ at an m.o.i. of 50 at $4{ }^{\circ} \mathrm{C}$. The histograms represent control noninfected DCs (dotted line), DCs with DMS1509(pAZ8) (fim sipB) (thin grey line) or DMS1508(pAZ8) (sipB) (thick black line). The data are from one experiment and represent reproducible data from three experiments. 
pISF101 with a deletion that eliminates fimbriation. E. coli expressing the Salmonella type 1 fimbriae interacted significantly better with DCs than the non-fimbriated E. coli after 30 or 60 min incubation at $37^{\circ} \mathrm{C}$ (Fig. 2a). Binding assays with GFP-expressing E. coli showed that $93 \%$ of the DCs were associated with fimbriated E. coli (Fig. 2b). In contrast, DCs incubated with E. coli (pKT303) did not bind any bacteria (Fig. 2b). Biotinylated purified type 1 fimbriae were found to bind in a dose-dependent manner to DCs (data not shown). Altogether, type 1 fimbrial expression was needed for efficient bacterial adhesion to the DCs.

\section{FimH-dependent binding to DCs}

The type 1 fimbriae of Salmonella bind to mannosylated glycoproteins on mammalian cells, and this interaction is mediated by their minor adhesive subunit FimH (Hancox et al., 1998). To determine whether the adhesin FimH mediated bacterial binding to DCs, fim $\mathrm{H}$ mutants producing wild-type strain levels of fimbriae were studied. Whether S. enterica serotype Typhimurium fim $\mathrm{H}^{-}$bound to DCs was evaluated by flow cytometry. As described by Hancox et al. (1998), S. enterica serotype Typhimurium LBH4, which has an insertionally inactivated fim $\mathrm{H}$ gene, produced type 1 fimbriae and agglutinated yeast cells only when complemented with pISF204 carrying fimHFZ. When complemented with pISF211, which contains fimFZ, only type 1 fimbriation was restored. Most of LBH4(pISF204) bound to DCs, as shown by flow cytometry, whereas the binding of LBH4 or LBH4(pISF211) was not significant and similar to the bacteria-free control (Fig. 3, top panel). The role of FimH in recognizing DC was also investigated with recombinant E. coli AAEC189(fim) complemented with plasmids pISF101( fim $\left.^{+}\right)$or pAZ36(fimH). Both E. coli AAEC189(pISF101) and AAEC189(pAZ36) produced similar amounts of type 1 fimbriae, but only the former bacteria agglutinated yeast cells and bound significantly to DCs, as shown in Fig. 3 (bottom panel). Moreover, the binding of type 1 fimbriated E. coli ORN103(pISF101) (Fig. 4) or S. enterica serotype Typhimurium AJB3 (data not shown) to DCs was impaired by $\alpha$-methyl mannoside. Nearly the whole population of DCs $(93 \%)$ associated with E. coli ORN103(pISF101) in the absence of the inhibitor, whereas most DCs (76\%) were free of bacteria in the presence of $\alpha$ methyl mannoside. This result demonstrated that $\alpha$-methyl mannoside efficiently blocks fimbriae-mediated bacterial binding to DCs, and thus that the type 1 fimbriae of $S$. enterica serotype Typhimurium most probably recognize one or more mannosylated glycoprotein receptor(s) on the DCs. This result also confirmed that the mannose-specific adhesin FimH was needed for DC recognition by Salmonella type 1 fimbriae.

\section{Fimbriae-mediated uptake by DCs}

We investigated whether type 1 fimbriae-dependent binding of Salmonella to DCs influences intracellular uptake. Both strains AJB3 and AJB4(fim) express SPI-1 T3SS that mediates cellular uptake by mammalian cells. To determine

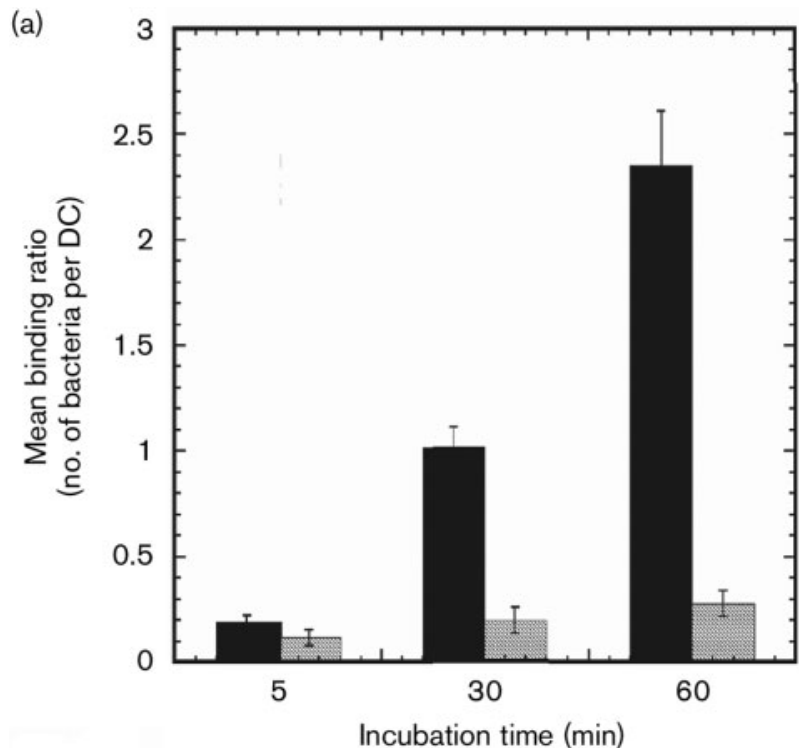

(b)

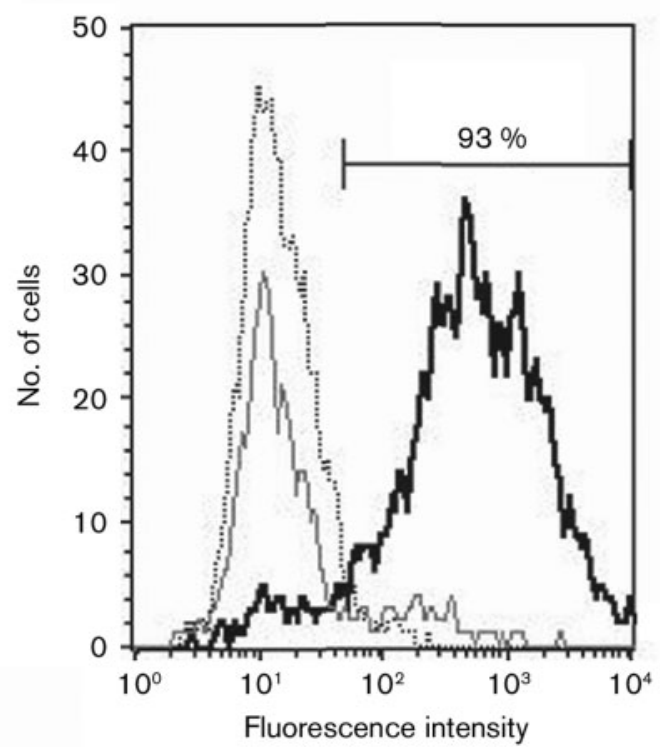

Fig. 2. Type 1 fimbriae-dependent binding of recombinant $E$. coli to DCs. (a) Type 1 fimbriated E. coli ORN103(pISF101) and nonfimbriated E. coli ORN103(pKT303) were incubated with DCs at $37^{\circ} \mathrm{C}$ for 5,30 or $60 \mathrm{~min}$. The numbers of bound bacteria per DC were counted microscopically. The bars represent the mean $\pm \mathrm{SE}$ values for ORN103(pISF101) (filled bars) and ORN103(pKT303) (shaded bars). There were statistically significant differences for the 30 and 60 min values $(P<0.01)$. (b) Bacterial binding to DCs analysed by flow cytometry. Only CD11 ${ }^{+}$-gated cells (DCs) are shown. DCs and bacteria were incubated for $30 \mathrm{~min}$ at an m.o.i. of 50 at $4{ }^{\circ} \mathrm{C}$. The histograms represent control non-infected DCs (dotted line), DCs with type 1 fimbriae-deficient ORN103(pKT303, pKKGFP) (thin grey line) or type 1 fimbriae-expressing ORN103(pISF101, pKKGFP) (thick black line).

whether SPI-1 was involved in internalization by DCs, a $\operatorname{sip} B$ mutant that expressed type 1 fimbriae (DMS1508) was included in the study. Standard invasion assays (gentamicin 


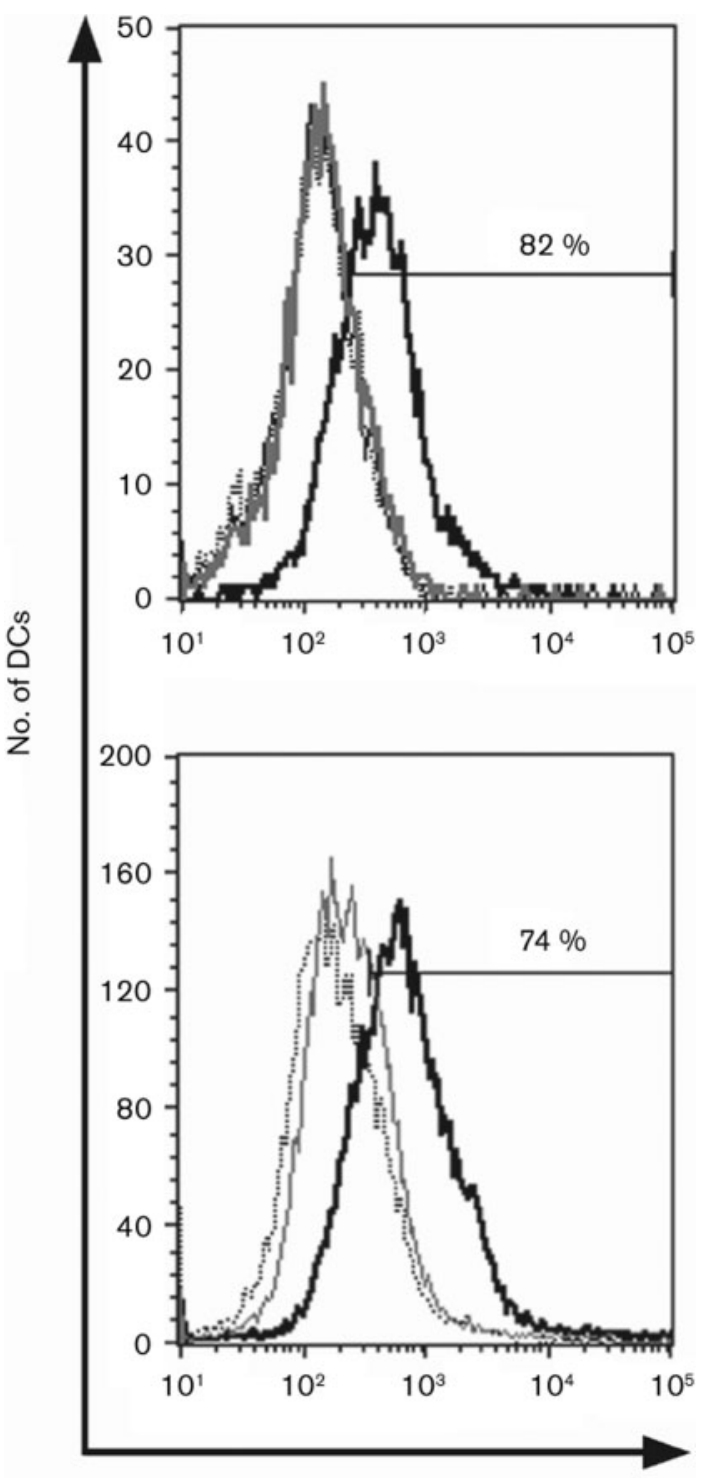

Fluorescence intensity
Fig. 3. FimH determines $S$. enterica serotype Typhimurium binding to DCs. DCs and bacteria were incubated at $4{ }^{\circ} \mathrm{C}$ for $30 \mathrm{~min}$, at an m.o.i. of 50 . Only CD $11 \mathrm{c}^{+}$-gated cells (DCs) are shown. Top panel: complementation of $S$. enterica serotype Typhimurium LBH4(fimH) with plasmids carrying (pISF204) or lacking (pISF211) fimH. Bacteria were transformed with GFPexpressing plasmid pAZ8. The histograms represent control non-infected DCs (dotted line), or DCs with LBH4(pAZ8) (thin black line), LBH4(pISF211, pAZ8) (grey line) or LBH4(pISF204, pAZ8) (thick black line). The former three histograms overlapped. Bottom panel: recombinant E. coli AAEC189 expressing non-adhesive or adhesive $S$. enterica serotype Typhimurium type 1 fimbriae from plasmid pAZ36 or pISF101, respectively. The histograms represent control non-infected DCs (dotted line), DCs with E. coli AAEC189(pAZ36, pAZ8) (thin grey line) or DCs with AAEC189(pISF101, pAZ8) (thick black line).

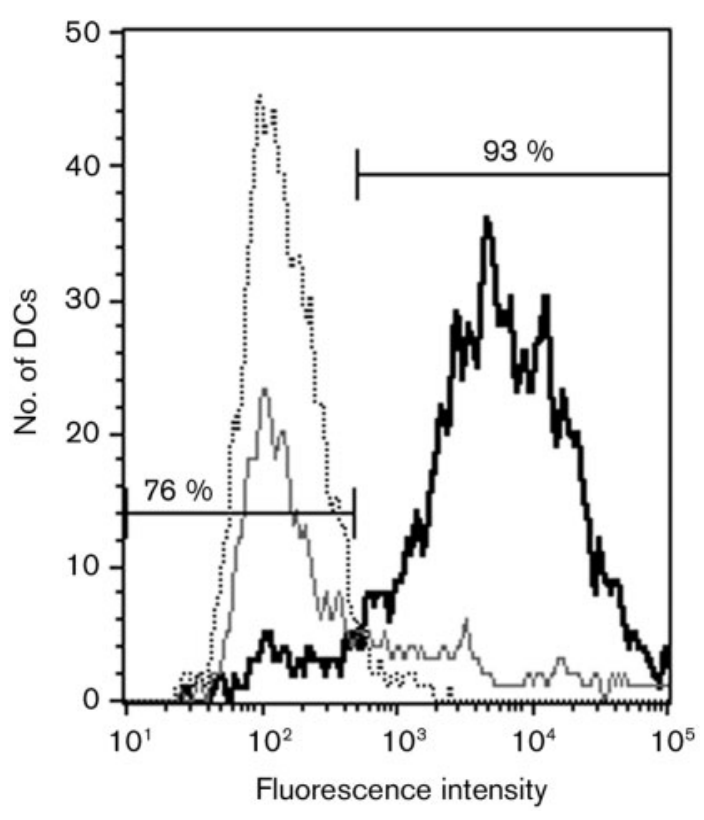

Fig. 4. Inhibition of FimH-mediated bacterial adhesion to DCs with $\alpha$-methyl mannoside. Bacteria were transformed with the GFP-expressing high-copy-number plasmid pKKGFP. DCs and bacteria were incubated as described in the legend to Fig. 3. The histograms represent control DCs stained with the appropriate isotype subclass (dotted line), or DCs incubated with recombinant E. coli ORN103 expressing adhesive S. enterica serotype Typhimurium type 1 fimbriae from plasmid pISF101, in the presence (grey thin line) or absence (black thick line) of $100 \mathrm{mM} \alpha$-methyl mannoside.

resistance) indicated that in comparison to the wild-type strain AJB3 (relative invasion of $100 \%$ ), significantly fewer AJB4(fim) cells were taken up by the DCs $(5.5 \pm 4.3 \%$, relative to AJB3, mean \pm SE of three independent experiments). In contrast, the uptake of DMS1508 ( sipB) (67 $\pm 6 \%$ of AJB3 invasion) was significantly less affected than the uptake of AJB4. These results indicated that SPI-1 does not affect the uptake of Salmonella by DCs as much as the type 1 fimbriae do. In contrast, DMS1508(sipB) was internalized significantly less efficiently by HeLa cells when compared to strain AJB3 ( $2.7 \pm 0.6 \%$ of AJB3 invasion), suggesting that Salmonella invasion of epithelial cells relied more on SPI-1 than Salmonella invasion of DCs. Strain AJB4( fim) was also significantly less invasive with HeLa cells $(0.6 \pm 0.3 \%$ of AJB3 invasion). This result was anticipated, since AJB4 ( $\mathrm{fim}$ ) had been previously shown to be significantly less adhesive and, as a consequence, less invasive than its parental strain AJB3 (Bäumler et al., 1996c). The cellular uptake of Salmonella was further analysed by flow cytometry using $\mathrm{O}$-antigen-specific antibody to label the bacteria and DC permeabilization to track the bacterial localization. Indeed, when DC membranes were permeabilized, both extra- and intracellular bacteria were detected by the antigen-specific antibody. The data are presented in Table 2 as the means of 
Table 2. Apparent percentage of DCs with intra- and extracellular Salmonella (flow cytometry data)

Values are means \pm SE of four independent experiments. All the data presented are based on apparent numbers, since DCs associated with one (or a few) bacteria might have escaped detection.

\begin{tabular}{|lcccc|}
\hline Strain & $\begin{array}{c}\text { Total DCs } \\
\text { counted }^{*}\end{array}$ & $\begin{array}{c}\text { Total DCs with } \\
\text { associated Salmonella }(\%) \dagger\end{array}$ & $\begin{array}{c}\text { DCs with extracellular } \\
\text { Salmonella }(\%)\end{array}$ & $\begin{array}{c}\text { DCs with intracellular } \\
\text { Salmonella }(\%) \ddagger\end{array}$ \\
\hline AJB3 & 23600 & $66.7 \pm 10.4(P<0.01) \S$ & $22.5 \pm 4.9(P<0.05) \S$ & $44.2 \pm 8.7(P<0.01) \S$ \\
DMS1508 & 26945 & $71.7 \pm 3.1(P<0.0001) \S$ & $30.4 \pm 5.1(P<0.05) \S$ & $41.3 \pm 3.4(P<0.0001) \S$ \\
AJB4 & 28228 & $10.4 \pm 2.4$ & $5.3 \pm 3.0$ & $5.1 \pm 0.9$ \\
\hline
\end{tabular}

${ }^{\star}$ DCs defined as cells positive for expression of CD11c.

$\dagger$ Permeabilized DCs with either internal, external, or both internal and external Salmonella.

¥DCs carrying only intracellular Salmonella (calculated as associated minus extracellular bacteria).

$\$ t$-Test comparisons with AJB4 data; there were no statistically significant differences between the AJB3 and DMS1508 data.

four experiments, one typical experiment being shown in Fig. 5. It should be noted that all the presented data are based on apparent numbers, since DCs associated with one (or a few) bacterium might have escaped detection. Among the DCs that were associated with the fimbriated Salmonella AJB3 $(66.7 \%$ of all DCs), a majority contained solely intracellular bacteria (Table 2). In contrast, only $10.4 \%$ of DCs were associated with the non-fimbriated Salmonella AJB4. There were also fewer DCs with only intracellular
AJB4 bacteria (5.1\% of all DCs). Most DCs (71.7\%) were associated with the fimbriated sipB mutant DMS1508, and a majority of these DCs carried Salmonella exclusively intracellularly. DC association of the non-fimbriated fim sipB double mutant (DMS1509) was similar to that found for the non-fimbriated fim strain AJB4 (data not shown). Taken together, these data showed that type 1 fimbriaemediated Salmonella association with DCs was the major determining factor for bacterial internalization.

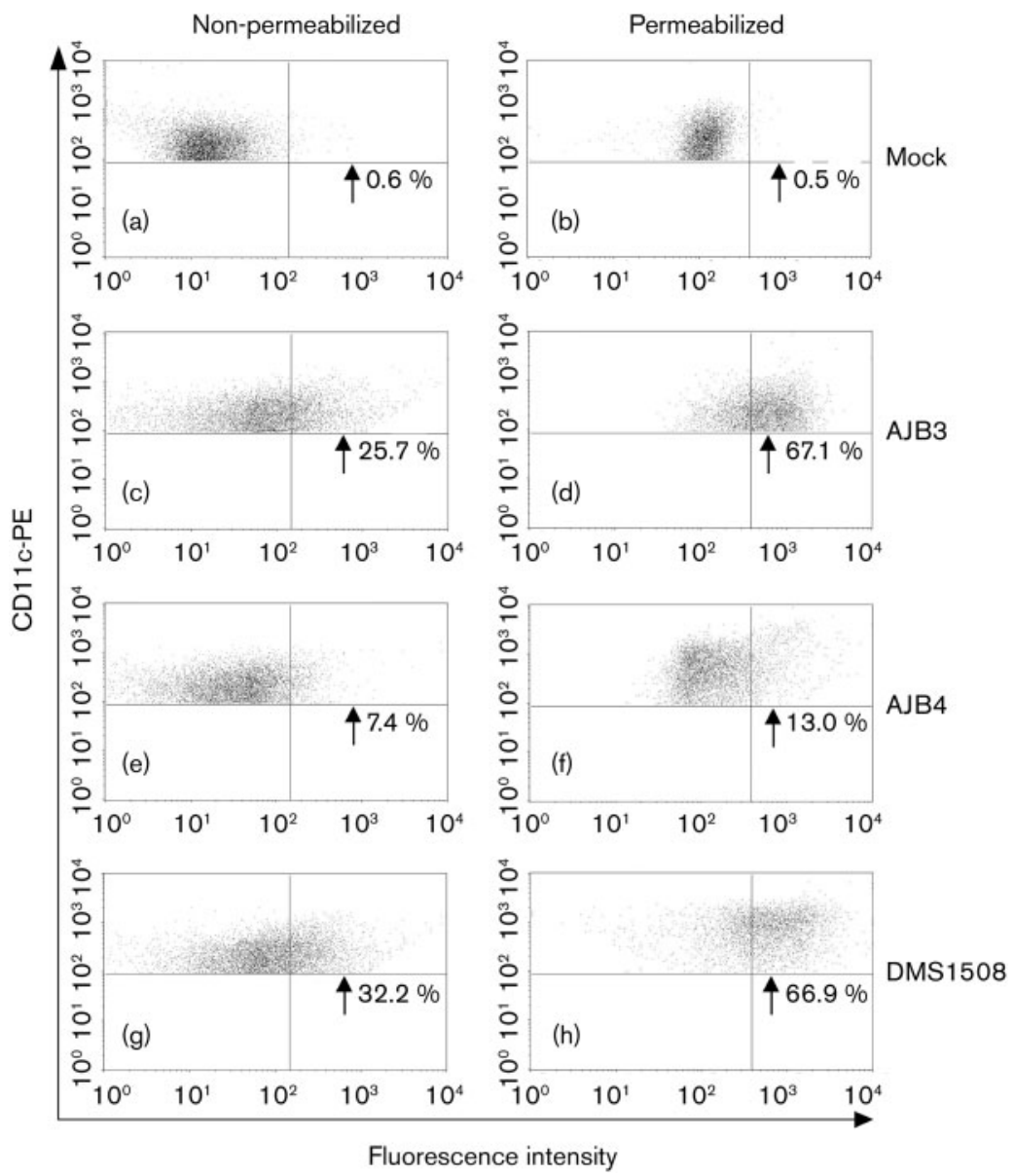

Fig. 5. Type 1 fimbriae-dependent internalization of $S$. enterica serotype Typhimurium by DCs. Strain AJB3 (c, d), AJB4 (fim) (e, f) or DMS1508 $(\operatorname{sip} B)(\mathrm{g}, \mathrm{h})$ were incubated with DCs for $30 \mathrm{~min}$ at an m.o.i. of 50 $\left(37^{\circ} \mathrm{C}\right)$. (a) and (b) represent mock-infected DCs. The DCs either were $(b, d, f, h)$ or were not (a, c, e, g) permeabilized. Bacteria were labelled with anti-O antigen antibodies, followed by FITC-conjugated secondary antibodies. Only CD $11 \mathrm{c}^{+}$-gated cells (DCs) are shown. The percentages represent the ratios of DCs carrying extracellular bacteria (a, c, e, g) or both extracellular and intracellular bacteria $(b, d, f, h)$. The data are from one experiment and represent reproducible data from four experiments. 


\section{DISCUSSION}

Following oral ingestion, S. enterica serotype Typhimurium reaches the intestines, where it first makes contact with $M$ cells, enterocytes and DC. There is evidence that DCs sending luminal dendrites or DCs within Peyer's patches interact closely with Salmonella (Niess et al., 2005; Rescigno et al., 2001; Salazar-Gonzalez et al., 2006). Although studies have identified that specific fimbriae preferentially target the Salmonella towards $\mathrm{M}$ cells or intestinal epithelial cells (Bäumler et al., 1996a, b), the bacterial ligand initiating the interaction with DCs is not known. This study showed that the type 1 fimbriae are extremely efficient at mediating the binding and internalization of $S$. enterica serotype Typhimurium into murine DCs. Whether binding directs bacterial uptake by creating the necessary conditions for other interactions to occur or by triggering bacterial internalization itself remains to be determined.

Microscopic analysis and flow cytometry showed that type 1 fimbriated S. enterica serotype Typhimurium, in contrast to an isogenic fim mutant, binds to bone-marrow-derived DCs, suggesting specificity of the fimbriae for one or more cell receptor(s). The binding specificity was confirmed with recombinant $E$. coli expressing $S$. enterica serotype Typhimurium type 1 fimbriae and with isolated fimbriae, which bound to DCs in a dose-dependent manner. The fimbrial structure consists of different types of subunits, all being encoded on the fim gene cluster, together with the chaperone-usher system that coordinates the export and assembly of the subunits (Clegg \& Swenson, 1994). The helically arranged structural subunit FimA forms most of the polymerized fimbrial shaft, whereas the binding determinant for mannosylated proteins is a minor structural subunit designated FimH (Hancox et al., 1998). Here, type 1 fimbriae-mediated Salmonella binding to DCs was shown to be mediated by the FimH adhesin. Moreover, this interaction was dependent on mannosylated residues. Strikingly, FimH-mediated binding was also required for efficient bacterial internalization. Under our experimental conditions, the SPI-1-encoded mammalian cell invasion machinery, did not significantly affect $S$. enterica serotype Typhimurium binding to DCs and was dispensable for DC invasion.

Type 1 fimbriae have previously been shown to confer $S$. enterica serotype Typhimurium adhesion to a variety of mammalian epithelial cells such as human Hep-2, HeLa, and small intestinal and bladder epithelial cell lines (Bäumler et al., 1996c; Boddicker et al., 2002; Hancox et al., 1998; Thankavel et al., 1999), and to contribute to the bacterial invasion of some of these cells (Bäumler et al., 1997; Ernst et al., 1990; Horiuchi et al., 1992; van der Velden et al., 1998). More recently, S. enterica serotype Typhimurium colonization of the murine intestine by biofilm formation was shown to require type 1 fimbriae carrying an adhesive allelic FimH (Boddicker et al., 2002). However, unlike epithelial cell internalization, which requires an active bacterial invasion machinery, the observed uptake of $S$. enterica serotype Typhimurium by DC was SPI-1-independent, as described recently by others (Kiama et al., 2006; Petrovska et al., 2004; van der Velden et al., 2003). A recent in vitro study with a macrophage cell line showed that the route of entry of SPI-1-induced, non-opsonized and complement- or IgG-opsonized Salmonella influenced their vacuolar surroundings and intracellular gene expression (Drecktrah et al., 2006). Salmonella uptake by murine DCs is greatly enhanced by serum complement (Eriksson et al., 2003). What mediated Salmonella binding and uptake remained unknown. The novel finding of this study is that the type 1 fimbriae-mediated binding of S. enterica serotype Typhimurium to DCs concomitantly targets the bacteria to the intracellular compartment of these professional migratory cells. The potential effect of fimbrial lectins on the phagocytic process of DCs was not evaluated in other studies (Drecktrah et al., 2006; Eriksson et al., 2003; Petrovska et al., 2004; van der Velden et al., 2003). DCs are known to recognize and take up bacteria and bacterial molecules via different groups of receptors, including C-type lectin and pattern recognition receptors (Geijtenbeek et al., 2004). One or more unidentified mannosylated DC glycoprotein(s) might represent a new class of phagocytic DC receptors that interact with bacterial lectins, such as the type 1 fimbriae of Salmonella. Whether this lectinophagocytic interaction (Ofek \& Sharon, 1988) directs uptake by a distinct mechanism of bacterial entry and triggers the formation of a new vacuolar compartment, as described for type 1 fimbriated E. coli with mast cells or macrophages (Baorto et al., 1997; Shin et al., 2000), is a question that requires further studies.

SPI-1 gene products are involved in the invasion of intestinal epithelial cells (Galan, 2001) and participate in M cell uptake (Penheiter et al., 1997). However, studies have suggested that SPI-1 is not essential for crossing the intestinal barrier in vivo (Clark et al., 1998; Jepson \& Clark, 2001; Murray \& Lee, 2000), and variable use of the SPI-1 proteins has been observed between host species and Salmonella serotypes (Morgan et al., 2004). Here, Salmonella uptake by murine DCs was mainly determined by FimH-mediated processes and not by its SPI-1-mediated invasive attributes. Although SPI-1 gene expression might not be optimal under the growth conditions used, recent microarray data showed that SipB and other SPI-1 genes are transcribed in stationary phase (Adkins et al., 2006). Moreover, since the SPI-1 apparatus and plasma membrane ruffling are activated within 2 min of macrophage exposure to $S$. enterica serotype Typhimurium grown to stationary phase (Alpuche-Aranda et al., 1994), it is unlikely that our interpretation of the data was significantly affected by the experimental conditions used for the adhesion assays presented. Nevertheless, it remains possible that SPI-1 plays some role in Salmonella uptake in vivo.

That Salmonella enterica serotype Typhimurium express their type 1 fimbriae in vivo was clearly shown in an earlier study which compared the bacterial colonization of murine 
organs two days after oral administration of a wild-type strain together with its isogenic fim mutant (Lockman \& Curtiss, III, 1992a). Higher numbers of the former strain were isolated from reticulo-endothelial tissues such as the spleen and liver. In contrast, more fim mutants were found in the blood. This observation is consistent with the more efficient uptake of $\mathrm{fim}^{+}$Salmonella by DCs, together with the previously described extraintestinal systemic distribution of Salmonella by CD18-expressing phagocytes (Vazquez-Torres et al., 1999) that were later postulated to be mainly DCs (Niess et al., 2005; Rescigno et al., 2001). In spite of the increased uptake of type 1 fimbriated S. enterica serotype Typhimurium by DCs, such strains were previously found to be less virulent than isogenic fim mutants in mice, as determined by their $\mathrm{LD}_{50}$ (Lockman \& Curtiss, III, 1992b; van der Velden et al., 1998). How the type 1 fimbriae attenuate S. enterica serotype Typhimurium in mice is not clear. Whether the targeting of Salmonella towards DCs amplifies an antibacterial inflammatory response in vivo, as expected from in vitro studies (Marriott et al., 1999; Yrlid et al., 2000), or whether S. enterica serotype Typhimuriumactivated resident DCs induce a non-inflammatory response with IL-10 secretion in mice, as observed with epithelialcell-conditioned human DCs in vitro remains to be determined (Rimoldi et al., 2005). Moreover, DC targeting is expected to affect the adaptive immune response (Bueno et al., 2005). In any case, the amplified interaction of type 1 fimbriated S. enterica serotype Typhimurium with DCs might play an important role in attenuating Salmonella, as observed with isogenic $\mathrm{fim}^{+}$and $\mathrm{fim}^{-}$strains (Lockman \& Curtiss, III, 1992b; van der Velden et al., 1998). By acting as 'anti-virulence' factors (Foreman-Wykert \& Miller, 2003), type 1 fimbriae might be beneficial to the intestinal establishment of S. enterica serotype Typhimurium as a persistent inhabitant of immunocompetent adult mice or carriers.

In this study, we showed that the expression of type 1 fimbriae optimized Salmonella uptake by DCs. Efficient bacterial internalization depended on the mannose-specific adhesin FimH and did not require SipB, an essential gene of the T3SS of Salmonella involved in epithelial cell invasion. The role of type 1 fimbriae-mediated binding and uptake of Salmonella by DCs and the importance of these interactions for infection remain to be investigated in the mammalian host.

\section{ACKNOWLEDGEMENTS}

We thank Corinne Tallichet-Blanc and Kendra Speirs for technical support, and Andreas Bäumler, Steve Clegg, Soman Abraham, Mark Goulian and Ian Blomfield for generously supplying bacterial strains or plasmids. We gratefully acknowledge all the ISREC scientists who supported this project by helpful discussions, particularly Florence Niedergang, Arnaud Didierlaurent, Frédéric Sierro, Nathalie Debard and Daniela Finke. We also thank David Artis, Huaiqing Chen and Leonard Bello for critical reading of the manuscript. This work was initiated during a sabbatical visit of D.M.S. to J.P. K.'s laboratory and was supported by US Department of Agriculture (USDA) Grant
37204-1986 and by Commonwealth of Pennsylvania Department of Agriculture Grant ME\#442342 to D.M.S. and Swiss National Science Foundation Grant 3100-067926.02 to J.P. K. A. G. was supported by the National Natural Science Foundation of China, Grant 30571386.

\section{REFERENCES}

Adkins, J. N., Mottaz, H. M., Norbeck, A. D., Gustin, J. K., Rue, J., Clauss, T. R., Purvine, S. O., Rodland, K. D., Heffron, F. \& Smith, R. D. (2006). Analysis of the Salmonella typhimurium proteome through environmental response towards infectious conditions. Mol Cell Proteomics 5, 1450-1461.

Alpuche-Aranda, C. M., Racoosin, E. L., Swanson, J. A. \& Miller, S. I. (1994). Salmonella stimulate macrophage macropinocytosis and persist within spacious phagosomes. J Exp Med 179, 601-608.

Baorto, D. M., Gao, Z., Malaviya, R., Dustin, M. L., van der Merwe, A., Lublin, D. M. \& Abraham, S. N. (1997). Survival of FimH-expressing enterobacteria in macrophages relies on glycolipid traffic. Nature 389, 636-639.

Bäumler, A. J., Tsolis, R. M., Bowe, F. A., Kusters, J. G., Hoffmann, S. \& Heffron, F. (1996a). The pef fimbrial operon of Salmonella typhimurium mediates adhesion to murine small intestine and is necessary for fluid accumulation in the infant mouse. Infect Immun 64, 61-68.

Bäumler, A. J., Tsolis, R. M. \& Heffron, F. (1996b). The lpf fimbrial operon mediates adhesion of Salmonella typhimurium to murine Peyer's patches. Proc Natl Acad Sci U S A 93, 279-283.

Bäumler, A. J., Tsolis, R. M. \& Heffron, F. (1996c). Contribution of fimbrial operons to attachment to and invasion of epithelial cell lines by Salmonella typhimurium. Infect Immun 64, 1862-1865.

Bäumler, A. J., Tsolis, R. M. \& Heffron, F. (1997). Fimbrial adhesins of Salmonella typhimurium. Role in bacterial interactions with epithelial cells. Adv Exp Med Biol 412, 149-158.

Blomfield, I. C., McClain, M. S. \& Eisenstein, B. I. (1991). Type 1 fimbriae mutants of Escherichia coli K12: characterization of recognized afimbriate strains and construction of new fim deletion mutants. Mol Microbiol 5, 1439-1445.

Boddicker, J. D., Ledeboer, N. A., Jagnow, J., Jones, B. D. \& Clegg, S. (2002). Differential binding to and biofilm formation on, HEp-2 cells by Salmonella enterica serovar Typhimurium is dependent upon allelic variation in the fimH gene of the fim gene cluster. Mol Microbiol 45, 1255-1265.

Bueno, S. M., Tobar, J. A., Iruretagoyena, M. I. \& Kalergis, A. M. (2005). Molecular interactions between dendritic cells and Salmonella: escape from adaptive immunity and implications on pathogenesis. Crit Rev Immunol 25, 389-403.

Cheminay, C., Schoen, M., Hensel, M., Wandersee-Steinhauser, A., Ritter, U., Korner, H., Rollinghoff, M. \& Hein, J. (2002). Migration of Salmonella typhimurium-harboring bone marrow-derived dendritic cells towards the chemokines CCL19 and CCL21. Microb Pathog 32, 207-218.

Clark, M. A., Hirst, B. H. \& Jepson, M. A. (1998). Inoculum composition and Salmonella pathogenicity island 1 regulate M-cell invasion and epithelial destruction by Salmonella typhimurium. Infect Immun 66, 724-731.

Clegg, S. \& Swenson, D. (1994). Salmonella fimbriae. In Fimbriae Adhesion, Genetics, Biogenesis and Vaccines, pp. 105-113. Edited by P. Klemm. Boca Raton: CRC Press.

Didierlaurent, A., Sirard, J. C., Kraehenbuhl, J. P. \& Neutra, M. R. (2002). How the gut senses its content. Cell Microbiol 4, 61-72. 
Dodd, D. C. \& Eisenstein, B. I. (1982). Antigenic quantitation of type 1 fimbriae on the surface of Escherichia coli cells by an enzyme-linked immunosorbent inhibition assay. Infect Immun 38, 764-773.

Drecktrah, D., Knodler, L. A., Ireland, R. \& Steele-Mortimer, O. (2006). The mechanism of Salmonella entry determines the vacuolar environment and intracellular gene expression. Traffic 7, 39-51.

Elsinghorst, E. A. (1994). Measurement of invasion by gentamicin resistance. Methods Enzymol 236, 405-420.

Eriksson, S., Chambers, B. J. \& Rhen, M. (2003). Nitric oxide produced by murine dendritic cells is cytotoxic for intracellular Salmonella enterica sv. Typhimurium. Scand J Immunol 58, 493-502.

Ernst, R. K., Dombroski, D. M. \& Merrick, J. M. (1990). Anaerobiosis, type 1 fimbriae, and growth phase are factors that affect invasion of HEp-2 cells by Salmonella typhimurium. Infect Immun 58, 2014-2016.

Foreman-Wykert, A. K. \& Miller, J. F. (2003). Hypervirulence and pathogen fitness. Trends Microbiol 11, 105-108.

Galan, J. E. (2001). Salmonella interactions with host cells: type III secretion at work. Annu Rev Cell Dev Biol 17, 53-86.

Geijtenbeek, T. B., van Vliet, S. J., Engering, A., 't Hart, B. A. \& van Kooyk, Y. (2004). Self- and nonself-recognition by C-type lectins on dendritic cells. Annu Rev Immunol 22, 33-54.

Hancox, L. S., Yeh, K. S. \& Clegg, S. (1998). Construction and characterization of type 1 non-fimbriate and non-adhesive mutants of Salmonella typhimurium. FEMS Immunol Med Microbiol 19, 289-296.

Hermant, D., Ménard, R., Arricau, N., Parsot, C. \& Popoff, M. Y. (1995). Functional conservation of the Salmonella and Shigella effectors of entry into epithelial cells. Mol Microbiol 17, 781-789.

Hersh, D., Monack, D. M., Smith, M. R., Ghori, N., Falkow, S. \& Zychlinsky, A. (1999). The Salmonella invasin SipB induces macrophage apoptosis by binding to caspase-1. Proc Natl Acad Sci U S A 96, 2396-2401.

Hopkins, S. A., Niedergang, F., Corthesy-Theulaz, I. E. \& Kraehenbuhl, J.-P. (2000). A recombinant Salmonella typhimurium vaccine strain is taken up and survives within murine Peyer's patch dendritic cells. Cell Microbiol 2, 59-68.

Horiuchi, S., Inagaki, Y., Okamura, N., Nakaya, R. \& Yamamoto, N. (1992). Type 1 pili enhance the invasion of Salmonella braenderup and Salmonella typhimurium to HeLa cells. Microbiol Immunol 36, 593-602.

Inaba, K., Inaba, M., Romani, N., Aya, H., Deguchi, M., Ikehara, S., Muramatsu, S. \& Steinman, R. M. (1992). Generation of large numbers of dendritic cells from mouse bone marrow cultures supplemented with granulocyte/macrophage colony-stimulating factor. J Exp Med 176, 1693-1702.

Jepson, M. A. \& Clark, M. A. (2001). The role of M cells in Salmonella infection. Microbes Infect 3, 1183-1190.

Kiama, S. G., Dreher, D., Cochand, L., Kok, M., Obregon, C., Nicod, L. \& Gehr, P. (2006). Host cell responses of Salmonella typhimurium infected human dendritic cells. Immunol Cell Biol 84, 475-481.

Lee, C. A., Jones, B. D. \& Falkow, S. (1992). Identification of a Salmonella typhimurium invasion locus by selection for hyperinvasive mutants. Proc Natl Acad Sci U S A 89, 1847-1851.

Lockman, H. A. \& Curtiss, III, R. (1992a). Virulence of non-type 1fimbriated and nonfimbriated nonflagellated Salmonella typhimurium mutants in murine typhoid fever. Infect Immun 60, 491-496.

Lockman, H. A. \& Curtiss, III, R. (1992b). Isolation and characterization of conditional adherent and non-type 1 fimbriated Salmonella typhimurium mutants. Mol Microbiol 6, 933-945.

Lostroh, C. P. \& Lee, C. A. (2001). The Salmonella pathogenicity island-1 type III secretion system. Microbes Infect 3, 1281-1291.
Lutz, M. B., Kukutsch, N., Ogilvie, A. L., Rossner, S., Koch, F., Romani, N. \& Schuler, G. (1999). An advanced culture method for generating large quantities of highly pure dendritic cells from mouse bone marrow. J Immunol Methods 223, 77-92.

Marriott, I., Hammond, T. G., Thomas, E. K. \& Bost, K. L. (1999). Salmonella efficiently enter and survive within cultured CD11c+ dendritic cells initiating cytokine expression. Eur J Immunol 29, 1107-1115.

Maurer, L. \& Orndorff, P. E. (1987). Identification and characterization of genes determining receptor binding and pilus length of Escherichia coli type 1 pili. J Bacteriol 169, 640-645.

Morgan, E., Campbell, J. D., Rowe, S. C., Bispham, J., Stevens, M. P., Bowen, A. J., Barrow, P. A., Maskell, D. J. \& Wallis, T. S. (2004). Identification of host-specific colonization factors of Salmonella enterica serovar Typhimurium. Mol Microbiol 54, 994-1010.

Murray, R. A. \& Lee, C. A. (2000). Invasion genes are not required for Salmonella enterica serovar Typhimurium to breach the intestinal epithelium: evidence that salmonella pathogenicity island 1 has alternative functions during infection. Infect Immun 68, 5050-5055.

Niedergang, F., Sirard, J. C., Blanc, C. T. \& Kraehenbuhl, J. P. (2000). Entry and survival of Salmonella typhimurium in dendritic cells and presentation of recombinant antigens do not require macrophage-specific virulence factors. Proc Natl Acad Sci U S A 97, 14650-14655.

Niess, J. H., Brand, S., Gu, X., Landsman, L., Jung, S., McCormick, B. A., Vyas, J. M., Boes, M., Ploegh, H. L. \& other authors (2005). CX3CR1-mediated dendritic cell access to the intestinal lumen and bacterial clearance. Science 307, 254-258.

Ofek, I. \& Sharon, N. (1988). Lectinophagocytosis: a molecular mechanism of recognition between cell surface sugars and lectins in the phagocytosis of bacteria. Infect Immun 56, 539-547.

Penheiter, K. L., Mathur, N., Giles, D., Fahlen, T. \& Jones, B. D. (1997). Non-invasive Salmonella typhimurium mutants are avirulent because of an inability to enter and destroy M cells of ileal Peyer's patches. Mol Microbiol 24, 697-709.

Petrovska, L., Aspinall, R. J., Barber, L., Clare, S., Simmons, C. P., Stratford, R., Khan, S. A., Lemoine, N. R., Frankel, G. \& other authors (2004). Salmonella enterica serovar Typhimurium interaction with dendritic cells: impact of the sifA gene. Cell Microbiol 6, 1071-1084.

Rescigno, M., Urbano, M., Valzasina, B., Francolini, M., Rotta, G., Bonasio, R., Granucci, F., Kraehenbuhl, J. P. \& Ricciardi-Castagnoli, P. (2001). Dendritic cells express tight junction proteins and penetrate gut epithelial monolayers to sample bacteria. Nat Immunol 2, 361-367.

Rimoldi, M., Chieppa, M., Salucci, V., Avogadri, F., Sonzogni, A., Sampietro, G. M., Nespoli, A., Viale, G., Allavena, P. \& Rescigno, M. (2005). Intestinal immune homeostasis is regulated by the crosstalk between epithelial cells and dendritic cells. Nat Immunol 6, 507-514.

Salazar-Gonzalez, R. M., Niess, J. H., Zammit, D. J., Ravindran, R., Srinivasan, A., Maxwell, J. R., Stoklasek, T., Yadav, R., Williams, I. R. \& other authors (2006). CCR6-mediated dendritic cell activation of pathogen-specific $\mathrm{T}$ cells in Peyer's patches. Immunity 24, 623-632.

Shin, J. S., Gao, Z. \& Abraham, S. N. (2000). Involvement of cellular caveolae in bacterial entry into mast cells. Science 289, 785-788.

Sierro, F., Dubois, B., Coste, A., Kaiserlian, D., Kraehenbuhl, J. P. \& Sirard, J. C. (2001). Flagellin stimulation of intestinal epithelial cells triggers CCL20-mediated migration of dendritic cells. Proc Natl Acad Sci U S A 98, 13722-13727.

Silhavy, T. J., Berman, M. L. \& Enquist, L. W. (1984). Experiments with Gene Fusion. Cold Spring Harbor, NY: Cold Spring Harbor Laboratory. 
Thankavel, K., Shah, A. H., Cohen, M. S., Ikeda, T., Lorenz, R. G., Curtiss, R., 3rd \& Abraham, S. N. (1999). Molecular basis for the enterocyte tropism exhibited by Salmonella typhimurium type 1 fimbriae. J Biol Chem 274, 5797-5809.

van der Velden, A. W., Baumler, A. J., Tsolis, R. M. \& Heffron, F. (1998). Multiple fimbrial adhesins are required for full virulence of Salmonella typhimurium in mice. Infect Immun 66, 2803-2808.

van der Velden, A. W., Velasquez, M. \& Starnbach, M. N. (2003). Salmonella rapidly kill dendritic cells via a caspase-1-dependent mechanism. J Immunol 171, 6742-6749.

Vazquez-Torres, A. \& Fang, F. C. (2000). Cellular routes of invasion by enteropathogens. Curr Opin Microbiol 3, 54-59.

Vazquez-Torres, A., Jones-Carson, J., Baumler, A. J., Falkow, S., Valdivia, R., Brown, W., Le, M., Berggren, R., Parks, W. T. \& Fang,
F. C. (1999). Extraintestinal dissemination of Salmonella by CD18expressing phagocytes. Nature 401, 804-808.

Wick, M. J. (2002). The role of dendritic cells during Salmonella infection. Curr Opin Immunol 14, 437-443.

Wick, M. J. (2003). The role of dendritic cells in the immune response to Salmonella. Immunol Lett 85, 99-102.

Yrlid, U., Svensson, M., Johansson, C. \& Wick, M. J. (2000). Salmonella infection of bone marrow-derived macrophages and dendritic cells: influence on antigen presentation and initiating an immune response. FEMS Immunol Med Microbiol 27, 313-320.

Zar, J. H. (1974). Biostatistical Analysis. Englewood Cliffs, NJ: Prentice-Hall.

Edited by: B. Kenny 